Pakistan Journal of Humanities and Social Sciences
Volume 8, Number 2, 2020, Pages $35-45$

\title{
Supply Chain Management Moderating Effect on the Nexus Amid Intensity of Energy Consumption and Accounting Information System
}

\author{
Waseem Yousaf ${ }^{1}$, Raheel Jamil ${ }^{2}$, Zardashia Nazir Chohan ${ }^{3}$, Muhammad Muneeb Akmal Mughal ${ }^{4}$ \\ ${ }^{1}$ MS Scholar, Minhaj University Lahore, Email: m.waseem511@gmail.com \\ ${ }^{2}$ Advocate, Associate Lawyer at (House of Lawyers), Email: raheeljamilkhan@gmail.com \\ ${ }^{3}$ Branch Operation Manager, MCB Bank Ltd., Email: ZardashiaNazirChohan@gmail.com \\ ${ }^{4}$ Scholar, Crescent Model Higher Secondary School Lahore., Email: wm93105@gmail.com
}

\begin{tabular}{|c|c|}
\hline \multicolumn{2}{|l|}{ ARTICLE INFO } \\
\hline Article History: & \\
\hline Received: & April 23, 2020 \\
\hline Revised: & May 07,2020 \\
\hline Accepted: & June 14,2020 \\
\hline Available Online: & June 30,2020 \\
\hline
\end{tabular}

\section{Keywords:}

Intensity of Energy

Effective Energy Consumption

Accounting Information System Supply Chain

\section{JEL Classification Codes:} E16, H83, M41, P28, P48, Q49,

\section{ABSTRACT}

The goal of the existing study is to explore the impact of the accounting information system (AIS) and the intensity of energy on the effective energy consumption of the sugar industry in Pakistan. The goal also consists of the moderating role of the effectiveness of the supply chain on the links of AIS and effective energy consumption, the intensity of energy, and effective energy consumption. The employees that are related to AIS and supply chain are the respondent and they provide the data by questionnaires and the data was evaluated by employing the effective tool of data analysis named Smart-PLS. The results show that AIS and intensity of energy have a positive link with effective energy consumption. The findings also show that the effectiveness of the supply chain positively moderates among the links of AIS and effective energy consumption, the intensity of energy, and effective energy consumption. The policymakers and the upcoming researchers will be the users of this study who can get guidelines in developing regulation regarding effective energy consumption and also in exploration of this area in the future.

(c) 2020 The Authors, Published by iRASD. This is an Open Access Article under the Creative Common Attribution Non-Commercial 4.0

Corresponding Author's Email: m.waseem511@gmail.com

\section{Introduction}

System of accounting information was recognized as an effective means of summarizing, recording, and validating the data of financial transactions prevailing in businesses whether in the current economies of past economies. While reviewing past literature, it is also analyzed that the work which was previously done on a manual basis is quite easier through computers in the current world. The recent development in information technologies has not only enhanced the working capabilities but also has contributed significantly towards the societies and global markets. In the perspective of reality, it is generally recognized that IT assumes a significant job in the field of bookkeeping; it tends to be vital weapons to help the item and system associations (Fitriati \& Mulyani, 2015). Some business associations get the upper hand by preparing new data frameworks.

Subsequently, associations will in general increment the cash for IT, which makes the proportion of IT venture to their all-out spending plan higher. In a period of worldwide rivalry, the way into an association's endurance is the constant improvement of its exhibitions. AIS of the past focused on the record, illustrating and favoring of data about business wealth-related trades. These limits were performed for the various social affairs inside the affiliation that was stressed over the specific decisions identified with budgetary accounting, administrative accounting, and duty stability issues(Bellosa, 2000). The need to facilitate these normally different frameworks prompted the clerk's valuation for shared databases that give a sturdy picture of the association's information, clearing out duplications and diminishing data conflicts (Nicolaou, 2000). The strong cases that innovation has had the most significant effect as 
accounting has been changed into an information administration calling have by and large been inadequately reflected in ongoing accounting research (Mamić Sačer \& Oluić, 2013).

Therefore, the tradition of research in the field of system of accounting information while concentrating the modeling of data structure, processing of transactions, securities, and computer frauds as well as the methodologies of development seemed not to be an effective mode presented for the understanding of accounting management and information technology via management control systems. Numerous compliments have been come up with some understandable means, where the effort of leading research via the establishment of the author has inserted a significant role in the financial development while ensuring the steady significant, flourishing, and sustainable activities in the system of the country (Feng, Sun, \& Zhang, 2009). This is because money related advancement is a significant course that will keep on boosting monetary development that will, thus, provoke venture, subsequently empowering a created budgetary marketplace (Al-Salem, 2015).

After this, a huge upgrading in the budgetary marketplace is thusly expected to yield an expanded pioneering enhancement that will highlight the inside and outer interest for energy. In a comparative example of thought attested that money related advancement allows the probability for the accessibility of a reasonable advance to get fabricating contraption, specifically machines, which would build the necessity of energy for skillful and effective fares (Reddy \& Ray, 2010). The inventor keeps on stating that if Granger causality moves from the use of force to fares or there is a causal attachment connecting fares and energy, at that point arrangements to monitor energy will diminish fares, and this could, thusly, decrease budgetary improvement. Then again, If causality was set up to be moving from fares to energy or substantiation of no Granger causality toward each path, at that point the creator declared that the most feasible and suffering option is to protect energy so that it won't affect trades (Nawaz, Azam, \& Bhatti, 2019).

The commitments of this examination are: Having respect to the prior, this examination expects to research to what degree the requirement for financial development impacts energy utilization in Nigeria (Chen, Zhou, Wang, \& Li, 2018). Notwithstanding that, what is the imaginable situation of $\mathrm{CO} 2$ discharges to the nation's monetary development possibilities, taking into account it being the mainly swarming nation in Africa and having the main oil stores and investigation? Is the resuscitated money related area of the nation giving any important financial commitments to the Gross domestic product? Is the Exchange receptiveness of the nation of any critical commitment? From these exact discoveries, the examination looks to decide the continuums of agreement suggestions that be present and the approach directs that could be accessible in accomplishing a practical and manageable monetary development prospect in the nation (Chima, 2007). The examination noted with distinct fascination the powerful difficulties of the country and the serious job of power as an important feature for feasible financial development.

To guarantee a tightfisted investigation, and relatively than other observational inquires about, that applied the ADF, PP, DF-GLS, KPSS, and Ng-Perron tests, the current examination practical the auxiliary test to distinguish conceivable basic breaks in the arrangement. Notwithstanding built up that the proficiency and intensity of positioning co-integration approaches by different techniques are touchy with the estimation of disturbance estimators. To keep away from this, built up an increasingly stingy co-integration strategy (Lecourt, Sigoillot, \& Petit-Conil, 2010). This methodology joins all non-co-integrating tests in building up a uniform, proficient, and solid co-integration gauges without different testing techniques.

This test is applied right now request to beat the feasible inadequacies of previously presented techniques. Following all these symptomatic examinations, the investigation practical the ARDL limits testing move toward within the sight of the basic sever, and this was approved utilizing the fare divide test, the inventive bookkeeping test, and the drive reaction analysis (Nawaz, Afzal, \& Shehzadi, 2013). By subsequent, the studies and the aim to resolve the elected issues in this study has significantly contributed to the overviews on the energy consumptions for many decades, while connecting monetary growth with the spending of power, the economic growth, and directness of trade and the economic growth influences by 
energy consumption. Further various strategies have been taken for the introduction of data the specification of models with the procedure of model estimation.

\section{Literature Review}

Many authors have employed data from different aspects while taking several companies in the overall global world. The authors viably endorsees the implementation and improvement of such software in the studied areas of research. The study further elaborates on the vast area of literature by constructing designs of the specific system "Integration of AIS" and further can have positively enumerated the functional relation amid the effectiveness of systems perceived (Brown, Dillard, \& Marshall, 2005). While discussing and examining the support of AIS, it is also observed that functions hypothesized the constraints of numerous contingencies which helps to intervene in the coordination of organization and requirements of controls. While reviewing literature about such area of study, it is also seen that the constraints that prevail in the society of organizational interactions have never been examined earlier before the interpretation of the AIS system in the structure of organizations.

In the sector of energy, there is a vast area of information sharing between certain departments which is functional in all organizations, such hazards that constrains the accounting system supplies could not efficiently enhance the operational activities of an organization and is also unable to support the results of participation from different aspects of the organization(Hartono \& Resosudarmo, 2008). The accounting system has not only enhanced the effectiveness of managing data within the organization but also has supported the compilation of data and information from the overall department to the final execution and striving the decision-making process. In the allocation of resources by higher managements, usually, the accounting system is somehow omitted due to nonuse, while the user is much effective as the decision-making process in an organization.

After analyzing, assessed the adequacy of automated accounting data frameworks in the Jordanian business banks considering mechanical improvement through testing the quality, adaptability, effortlessness, and secrecy of these frameworks(Figge \& Hahn, 2013). In this way, they built up a survey and conveyed (45) poll to the money related offices in business banks recorded on the Stock Trade of Amman. Plenty of data has been taken in the study with ultimate returns and purpose of sustainable analysis while implying the means of the banking sector where the categories of risk are prevailing at some higher stages(Shen, Ding, Chen, \& Chan, 2017). Most of the studies regarding energy consumption link the issues prevail in the decades ago, the link is found to be directed in the implementation of some strategies to bump the systems of accounting information into the consumption of energies. The EKC theory is an experimental examination that tests the existence of an altered $U$ molded association among monetary growth and ecological quality(Recalde \& Ramos-Martin, 2012). Accessible looks into involving considered the different situations of the Natural Kuznets Bend (EKC) as for various nations, applying distinctive econometric strategies for examinations and while shifting financial condition.

In a related improvement, to give some examples investigated the affiliation connecting income and discharges of power utilization. The creators in their discoveries proved the existence of the EKC in the divide study regions (Duro \& Padilla, 2011). As opposed to that, utilized board information and offered questionable results concerning money related advancement and energy consumption discharges' affiliation. Studies on their part upheld the exact accessibility of the EKC in Brazil, India, China, Pakistan, France, Malaysia, Italy, and Romania (Aziziankohan, Jolai, Khalilzadeh, Soltani, \& Tavakkoli-Moghaddam, 2017). In another exploration exertion further investigated the dynamic affiliation connecting energy consumption outflows, incomes, and utilization of power in the US. Their outcome delineated that power spending discharges are the Granger reason in incomes, while power utilization has a remarkable job in the heightening of energy consumption in the US. A similar equivalent work out was completed in Malaysia and France individually, the results of their exact exercise showed how money related advancement Granger reason an expansion in the utilization of power which brings about the emanation of carbon in Malaysia and France (Velasco \& Roth, 2010).

Notwithstanding that, a unidirectional causality is watched originating from money related advancement to energy utilization (Hang \& Tu, 2007). While utilizing a board of 43 
creating nations set up the presence of ecological Kuznets' bend (EKC) theory in the contemplated territories. The discoveries of the creators set up that the salary of a nation increments concerning its capacity to lessen the all-out substance of its energy consumption discharges. Studies that practical late econometric dealings could be initiate in the central investigation. In that evaluation the creators practical the next era Unit root test, crosssectional improved (CADF) in addition to the cross-sectional extended (CIPS) unit root tests, and the Lagrange multiplier bootstrap panel co-integration test (Xu, Xiang, Nijkamp, \& Higano, 2013). The point of every one of these philosophies is to dissect the since a long time ago run association that may exist among carbon dioxide outflows, genuine total national output (Gross domestic product) in the primary occasion and the square of genuine Gross domestic product in the subsequent example(Lee et al., 2017). The investigation likewise included energy utilization, exchange, and the travel industry under an Ecological Kuznets Bend (EKC) copy for the association for financial co-activity and advancement (OECD) nations (Sajjad Hussain, Muhaizam Bin Musa, \& Omran, 2018).

The discoveries of the study built up a connection between power utilization and the journey industry. In a connected improvement, the investigation discovered how a persistent ascent in worldwide exchange could help in improving the ecological nature of the landmasses below evaluate. Notwithstanding this improvement, a depressing association was found among the EKC theories, Gross domestic product (Ang, 1994). The effects and ramifications of energy consumption discharge on the Gross domestic product and the earth completely rely upon the sort and substance of energy outflows. For example, energy consumption discharges, sulfur dioxide, and carbon monoxide effectively affect human wellbeing and the earth. To help this view, the investigation found how the connection between energy consumption emanations and monetary development is recognized to be measurably critical. This improvement verified the presence of altered $U$-shaped discoveries is the investigation. In that review, the creator set up the presence of a noteworthy connection between monetary development and expanding energy spending discharges in Taiwan (Nawaz et al., 2013).

To explain how affecting is the existence of power consumption in the Taiwanese financial system, the inventor keeps up that the Taiwanese Gross domestic invention would have been $34 \%$ less had it been power spending outflows is balanced out as contrasted and that of the 1990 level. In their trial examination establish the presence of a helpful relationship among reasonable financial improvement and power emanations (Howarth, Schipper, Duerr, \& Strøm, 1991). Praising this finding is the honorable research discoveries in that examination exertion, the creator keeps up the viewpoint that monetary development and the abatement of natural corruption are perfect as per the EKC theory. Studies set up the existence of a positive connection among power spending outflows and monetary development at various times of their examinations. As already given, set up a depressing association among financial development and the per capita corruption emanations in the long-run(Zhao, Guo, \& Zhao, 2018). In another advancement, investigated the causal affiliation connecting the utilization of energy, incomes, and emanations of energy consumption by counting speculation and work as further controllers of discharges of carbon however watched no causality connecting energy spending outflows and incomes (Hussain et al., 2012).

The observational evidence from their exploration set up that budgetary advancement, exchange transparency, monetary development, and associations need to capacity to restrict the pulverization of the biology while supporting the accessibility of the EKC idea. Supplementing the exploration discoveries in their investigation on China, built up that monetary area arrangements ought to be urged to encourage the work of current innovation by organizations that have the possibilities of lessening energy consumption emanations, as well as that, will similarly help in the effective improvement of the nearby yield (Yuan, Kang, Zhao, \& Hu, 2008). Notwithstanding this point, the creators keep on keeping up that money related improvement energizes capitalization, and monetary guidelines that help biological gauges ought to similarly be persuaded with the modern segments. Plenty of investigations have been a performance to minimize the effects of such contributions, where a certain investigation has put a further impact on the economic growth while consuming energy and development of financial businesses on the emission of carbon. For the sake of standards of ecology, the openness of trade, the development of economies, and the consumption of 
energies will be an effective means of overcoming issues. The study includes a certain hypothesis, which is as follows:

H1: There is a significant association between the accounting information system and the effectiveness of energy consumption in the sugar industry in Pakistan.

H2: There is a significant association between the intensity of energy and the effectiveness of energy consumption in the sugar industry in Pakistan.

H3: Effectiveness of the supply chain moderates the relation between accounting information systems and effective energy consumption in the sugar industry in Pakistan.

H4: Effectiveness of the supply chain moderates the relation between the intensity of energy and effective energy consumption in the sugar industry in Pakistan.

\section{Research Methods}

The goal of the existing study is to explore the impact of the accounting information system (AIS) and the intensity of energy on the effective energy consumption of the sugar industry in Pakistan. The goal also consists of the moderating role of the effectiveness of the supply chain on the links of AIS and effective energy consumption, the intensity of energy, and effective energy consumption. The employees that are related to AIS and supply chain are the respondent and they provide the data by questionnaires and the data was evaluated by employing the effective tool of data analysis named Smart-PLS. Around 710 questionnaires were distributed by the researcher among the respondents by personal visit and after 15 days only 590 questionnaires were received back and used for the analysis that represents around 83.09 percent response rate. The accounting information system (AIS) has 8 items, the intensity of energy (IE) has 6 items, effectiveness of supply chain (ESC) has 10 items and effective energy consumption (EEC) has 5 items and these variables are shown in Figure 1.

\section{Theoretical Framework}

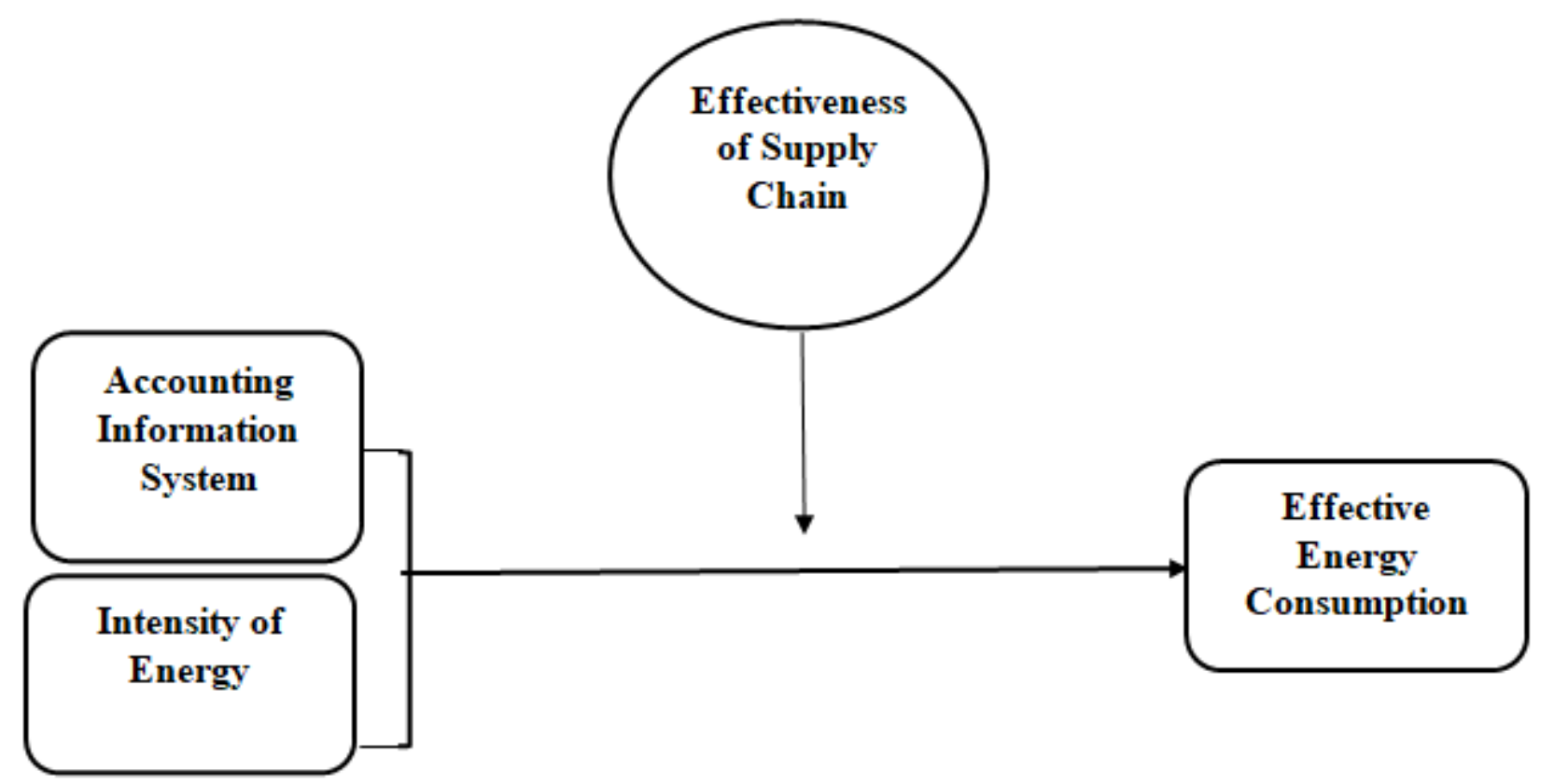

Figure 1: Theoretical Framework

\section{Findings}

The findings firstly exposed the convergent validity that shows the correlation of the items with each other and the figure shows that the Alpha values are more than 0.70 while CR values also higher than 0.70 , AVE values are also more than 0.50 and loadings are larger than 0.50 that is the indication of valid convergent validity. These figures are shown in Table 1.

The findings secondly exposed the discriminant validity that shows the construct's correlation with each other and the figure shows that the values of a particular variable are larger than the other variables that are the indication of valid discriminant validity. These figures are shown in Table 2. 
Table 1: Convergent Validity

\begin{tabular}{|c|c|c|c|c|c|}
\hline Constructs & Loadings & Items & Alpha & CR & AVE \\
\hline \multirow{8}{*}{$\begin{array}{c}\text { Accounting Information } \\
\text { System }\end{array}$} & AIS1 & 0.834 & \multirow{8}{*}{0.941} & \multirow{8}{*}{0.951} & \multirow{8}{*}{0.710} \\
\hline & AIS2 & 0.862 & & & \\
\hline & AIS3 & 0.848 & & & \\
\hline & AIS4 & 0.813 & & & \\
\hline & AIS5 & 0.869 & & & \\
\hline & AIS6 & 0.869 & & & \\
\hline & AIS7 & 0.853 & & & \\
\hline & AIS8 & 0.787 & & & \\
\hline \multirow{6}{*}{ Intensity of Energy } & IE1 & 0.956 & \multirow{6}{*}{0.959} & \multirow{6}{*}{0.968} & \multirow{6}{*}{0.835} \\
\hline & IE2 & 0.823 & & & \\
\hline & IE3 & 0.955 & & & \\
\hline & IE4 & 0.957 & & & \\
\hline & IE5 & 0.821 & & & \\
\hline & IE6 & 0.957 & & & \\
\hline \multirow{9}{*}{$\begin{array}{c}\text { Effectiveness of Supply } \\
\text { Chain }\end{array}$} & ESC1 & 0.568 & \multirow{9}{*}{0.919} & \multirow{9}{*}{0.925} & \multirow{9}{*}{0.589} \\
\hline & ESC10 & 0.890 & & & \\
\hline & ESC2 & 0.568 & & & \\
\hline & ESC3 & 0.883 & & & \\
\hline & ESC4 & 0.904 & & & \\
\hline & ESC5 & 0.568 & & & \\
\hline & ESC6 & 0.891 & & & \\
\hline & ESC7 & 0.904 & & & \\
\hline & ESC8 & 0.575 & & & \\
\hline \multirow{4}{*}{$\begin{array}{l}\text { Effective Energy } \\
\text { Consumption }\end{array}$} & EEC1 & 0.809 & \multirow{4}{*}{0.852} & \multirow{4}{*}{0.900} & \multirow{4}{*}{0.692} \\
\hline & EEC2 & 0.840 & & & \\
\hline & EEC4 & 0.864 & & & \\
\hline & EEC5 & 0.813 & & & \\
\hline
\end{tabular}

Table 2: Fornell Larcker

\begin{tabular}{ccccc}
\hline & AIS & IE & ESC & EEC \\
\hline AIS & 0.842 & & & \\
IE & 0.398 & 0.914 & & \\
ESC & 0.570 & 0.489 & 0.767 & 0.832 \\
EEC & 0.416 & 0.508 & 0.436 & \\
\hline
\end{tabular}

The findings also show the second method of checking the discriminant validity called cross-loadings that show the constructs correlation with each other and the figure shows that the values of a particular variable are larger than the other variables that are the indication of valid discriminant validity. These figures are shown in Table 3.

Table 3: Cross-loadings

\begin{tabular}{lcccc}
\hline & AIS & IE & ESC & EEC \\
\hline AIS1 & $\mathbf{0 . 8 3 4}$ & 0.291 & 0.465 & 0.330 \\
AIS2 & $\mathbf{0 . 8 6 2}$ & 0.341 & 0.488 & 0.353 \\
AIS3 & $\mathbf{0 . 8 4 8}$ & 0.305 & 0.455 & 0.321 \\
AIS4 & $\mathbf{0 . 8 1 3}$ & 0.353 & 0.500 & 0.303 \\
AIS5 & $\mathbf{0 . 8 6 9}$ & 0.345 & 0.499 & 0.324 \\
AIS6 & $\mathbf{0 . 8 6 9}$ & 0.360 & 0.491 & 0.391 \\
AIS7 & $\mathbf{0 . 8 5 3}$ & 0.372 & 0.482 & 0.417 \\
AIS8 & $\mathbf{0 . 7 8 7}$ & 0.308 & 0.464 & 0.340 \\
IE1 & 0.347 & $\mathbf{0 . 9 5 6}$ & 0.448 & 0.468 \\
IE2 & 0.392 & $\mathbf{0 . 8 2 3}$ & 0.442 & 0.460 \\
IE3 & 0.349 & $\mathbf{0 . 9 5 5}$ & 0.447 & 0.471 \\
IE4 & 0.351 & $\mathbf{0 . 9 5 7}$ & 0.450 & 0.460 \\
IE5 & 0.395 & $\mathbf{0 . 8 2 1}$ & 0.445 & 0.454 \\
IE6 & 0.347 & $\mathbf{0 . 9 5 7}$ & 0.443 & 0.466 \\
ESC1 & 0.679 & $\mathbf{0 . 1 8 7}$ & $\mathbf{0 . 5 6 8}$ & 0.164 \\
\hline
\end{tabular}




\begin{tabular}{lllll}
\hline ESC10 & 0.406 & 0.465 & $\mathbf{0 . 8 9 0}$ & 0.403 \\
ESC2 & 0.667 & 0.183 & $\mathbf{0 . 5 6 8}$ & 0.159 \\
ESC3 & 0.418 & 0.462 & $\mathbf{0 . 8 8 3}$ & 0.420 \\
ESC4 & 0.377 & 0.471 & $\mathbf{0 . 9 0 4}$ & 0.424 \\
ESC5 & 0.676 & 0.187 & $\mathbf{0 . 5 6 8}$ & 0.179 \\
ESC6 & 0.399 & 0.469 & $\mathbf{0 . 8 9 1}$ & 0.410 \\
ESC7 & 0.376 & 0.467 & $\mathbf{0 . 9 0 4}$ & 0.421 \\
ESC8 & 0.678 & 0.199 & $\mathbf{0 . 5 7 5}$ & 0.180 \\
EEC1 & 0.320 & 0.377 & 0.290 & $\mathbf{0 . 8 0 9}$ \\
EEC2 & 0.339 & 0.493 & 0.389 & $\mathbf{0 . 8 4 0}$ \\
EEC4 & 0.366 & 0.446 & 0.427 & $\mathbf{0 . 8 6 4}$ \\
EEC5 & 0.361 & 0.358 & 0.330 & $\mathbf{0 . 8 1 3}$ \\
\hline
\end{tabular}

The findings also show the third method of checking the discriminant validity called the Heterotrait Monotrait (HTMT) ratio that shows the constructs correlation with each other and the figure shows that the values of the ratio are lower than 0.90 that is the indication of valid discriminant validity. These figures are shown in Table 4.

Table 4: Heterotrait Monotrait Ratio

\begin{tabular}{lllll}
\hline & AIS & IE & ESC & EEC \\
\hline AIS & & & & \\
IE & 0.4180 & & & \\
ESC & 0.7180 & 0.4690 & \\
EEC & 0.4600 & 0.5560 & 0.4390 & \\
\hline
\end{tabular}

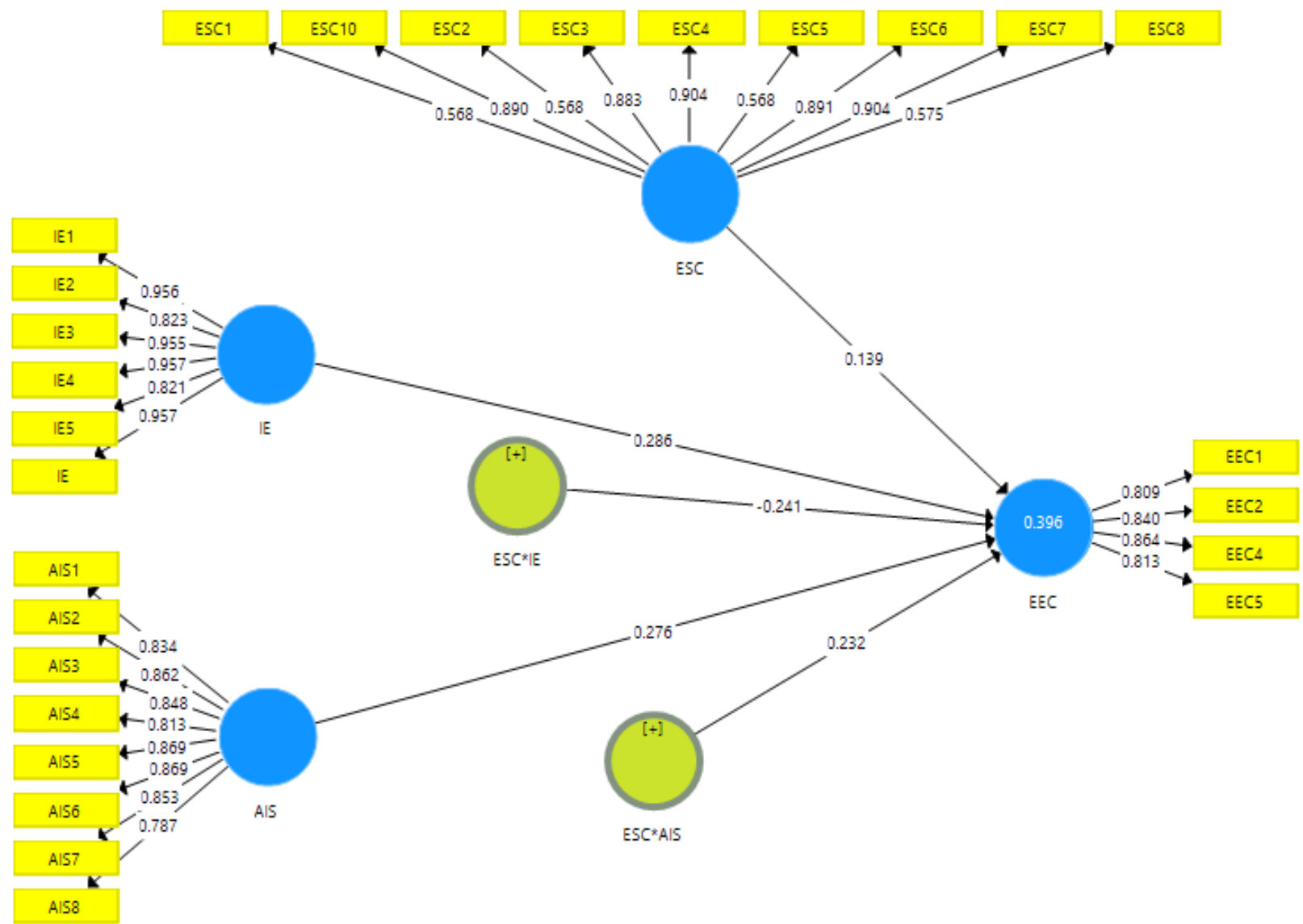

Figure 2: Measurement Model Assessment

The regression results show that AIS and intensity of energy have a positive link with the effective energy consumption and accept $\mathrm{H} 1$ and $\mathrm{H} 2$. Besides, the results of path analysis also show that the effectiveness of the supply chain has positively moderation among the links of AIS and effective energy consumption, the intensity of energy, and effective energy consumption in the sugar industry of Pakistan. These path analyses are shown in Table 5 shown below: 
Table 5: Path Analysis

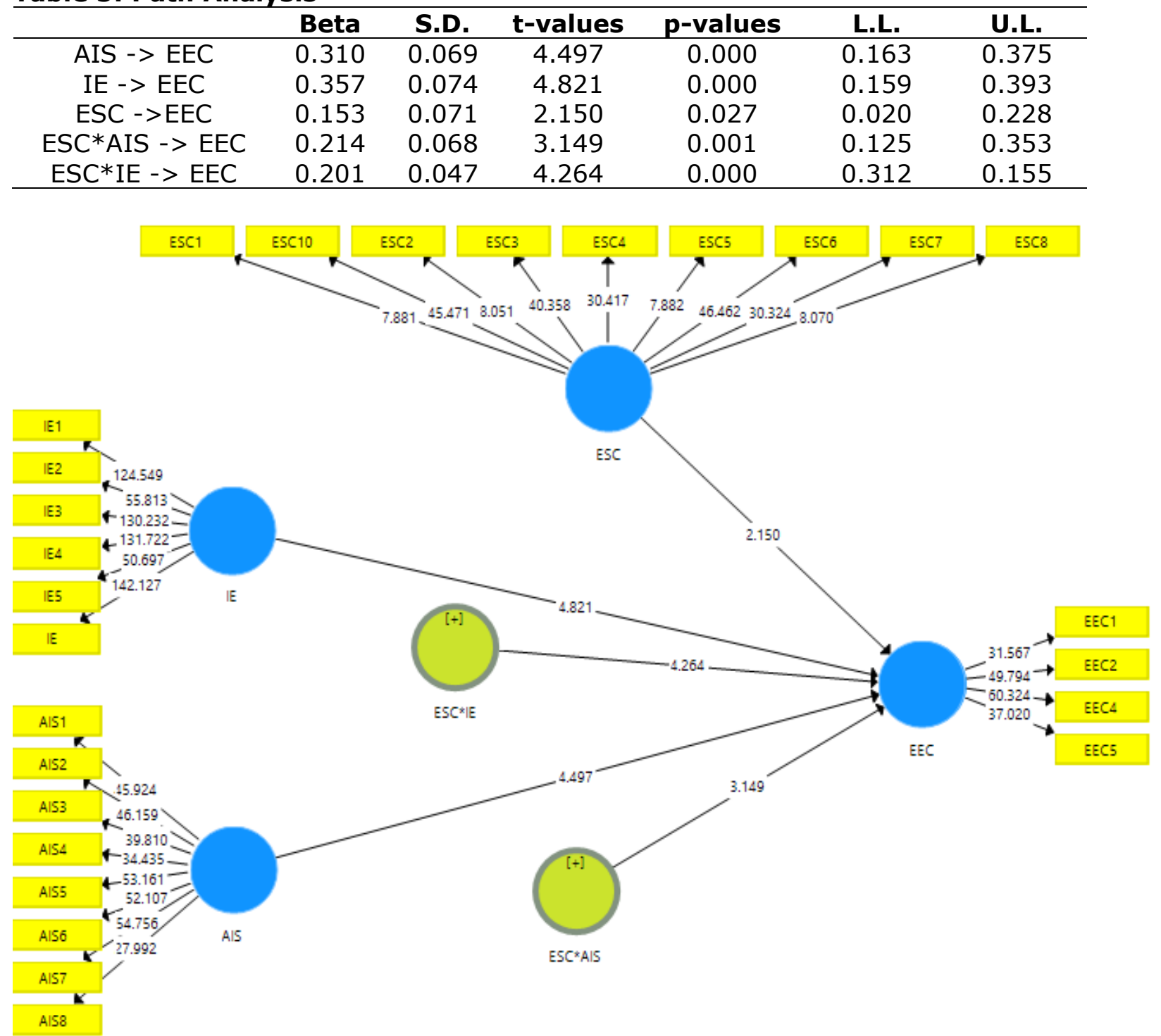

Figure 3: Structural Model Assessment

\section{Discussions}

The results show that AIS and intensity of energy have a positive link with effective energy consumption. The findings also show that the effectiveness of the supply chain positively moderates among the links of AIS and effective energy consumption, the intensity of energy, and effective energy consumption. The policymakers and the upcoming researchers will be the users of this study who can get guidelines in developing regulation regarding effective energy consumption and also in exploration of this area in the future. AIS not only supports the decision-making process and managing the data works within all organizational structure but also helps to see the insights of organizations via implementing strong measures in the organization and helping for the success of the system and dynamic implementation (Sadorsky, 2010). It is not contrary to the above issue of constraints to be resolved at first, but the important task which is compulsory to be resolved is to implement an effective accounting information system to get prompt results for analyzing the growth and structure of an organization. Studies suggested that further research ought to be directed in this region. Further investigated the reasons for declining a fruitful execution of ERP framework in Egypt. Studies contemplated (45) Egyptian organizations that apply ERP framework in Egypt. Studies inferred that the information or culture-based influenced the utilization of the ERP framework adversely. Moreover, decided on the effect of the utilization of data innovation on the adequacy of accounting data frameworks.

The study considered the money related establishments recorded in the Primary Market in Amman Stock Trade which comprises of (23) monetary organizations including banks and 
insurance agencies. Two surveys were created and appropriated to some of the money related and data innovation divisions of these organizations. Means and frequencies were utilized to depict the example of the study (Somavat, Jadhav, \& Namboodiri, 2010). Likewise, a t-test was utilized to test the critical theories of the investigation. The study discovered there is sway for data innovation on the viability of accounting data frameworks. The study prescribed that there is a need to focus on preparing and more investigates these issues. Studies planned to analyze the long-term money related execution because of changes in the ERP framework (Vanek \& Sun, 2008). The outcomes uncovered that organizations that actualize the ERP framework demonstrated early upgrades in the monetary exhibition more than others.

\section{Conclusion}

In the end, this study concludes that the sugar industry in Pakistan has implemented effective supply chain practices along with the AIS in the organization that enhances the effective energy consumption in the firm that enhances their performance. Further executed the multivariate causality evaluation with an end goal to survey the causal affiliation connecting money related improvement, utilization of energy, and energy consumption outflows. The creator utilized time arrangement information from China. The results from the exploration unveiled that money related improvement Granger causes energy utilization which thus brings about power spending depletion. Utilizing Turkish information, build up a finding that connects the speculations between monetary improvement and energy spending emanations. While utilizing South African information found that utilization of power Granger causes energy consumption discharges and that budgetary advancement is being Granger brought about by emanations of energy consumption. Interestingly, we re-explored the causality connecting the utilization of energy, budgetary advancement, and outflows of energy consumption. Right now unidirectional causality was built up moving from budgetary development to energy spending emanations (Giridharan \& Emmanuel, 2018). In another strand of energy writing, investigated the contact of wealth-related improvement and monetary growth on energy consumption emanations in the occasion of board nations that incorporate China, Russia, the US, Brazil, and India, and in this manner investigated the capacity of associations on energy consumption discharges (Hussain, Mosa, \& Omran, 2017).

\section{Limitations and Future Directions}

This study has some limitations like it takes only AIS and intensity of energy as predictors and ignored the other factors that affect the effective energy consumption and suggestion for future studies that they should incorporate this point in their analysis. Besides, the current study also ignored the mediating role of effective energy consumption and future study should incorporate it also in their analysis. The results of the existing study will implement only in Pakistan and future studies should add more studies to expand the scope of their literature.

\section{References}

Al-Salem, S. (2015). Carbon dioxide (CO2) emission sources in Kuwait from the downstream industry: Critical analysis with a current and futuristic view. Energy, 81, 575-587.

Ang, B. W. (1994). Decomposition of industrial energy consumption: the energy intensity approach. Energy Economics, 16(3), 163-174. doi: https://doi.org/10.1016/01409883(94)90030-2

Aziziankohan, A., Jolai, F., Khalilzadeh, M., Soltani, R., \& Tavakkoli-Moghaddam, R. (2017). Green supply chain management using the queuing theory to handle congestion and reduce energy consumption and emissions from supply chain transportation fleet. Journal of Industrial Engineering and Management (JIEM), 10(2), 213-236. doi: http://dx.doi.org/10.3926/jiem.2170

Bellosa, F. (2000). The benefits of event: driven energy accounting in power-sensitive systems. Paper presented at the Proceedings of the 9th workshop on ACM SIGOPS European workshop: beyond the PC: new challenges for the operating system.

Brown, D. L., Dillard, J. F., \& Marshall, R. S. (2005). Strategically informed, environmentally conscious information requirements for accounting information systems. Journal of Information Systems, 19(2), 79-103. doi: https://doi.org/10.2308/jis.2005.19.2.79

Chen, J., Zhou, C., Wang, S., \& Li, S. (2018). Impacts of energy consumption structure, energy intensity, economic growth, urbanization on PM2. 5 concentrations in countries globally. Applied energy, 230, 94-105. doi: https://doi.org/10.1016/j.apenergy.2018.08.089 
Chima, C. M. (2007). Intensity of energy use in the USA: 1949-2003. Journal of Business \& Economics Research (JBER), 5(11). doi: https://doi.org/10.19030/jber.v5i11.2599

Duro, J. A., \& Padilla, E. (2011). Inequality across countries in energy intensities: An analysis of the role of energy transformation and final energy consumption. Energy Economics, 33(3), 474-479. doi: https://doi.org/10.1016/j.eneco.2010.12.008

Feng, T., Sun, L., \& Zhang, Y. (2009). The relationship between energy consumption structure, economic structure and energy intensity in China. Energy Policy, 37(12), 5475-5483. doi: https://doi.org/10.1016/j.enpol.2009.08.008

Figge, F., \& Hahn, T. (2013). Value drivers of corporate eco-efficiency: Management accounting information for the efficient use of environmental resources. Management Accounting Research, 24(4), 387-400. doi: https://doi.org/10.1016/j.mar.2013.06.009

Fitriati, A., \& Mulyani, S. (2015). The imfluence of leadership style on accounting information system success and its impact on accounting information quality. Research Journal of Finance and Accounting, 6(11), 167-173.

Giridharan, R., \& Emmanuel, R. (2018). The impact of urban compactness, comfort strategies and energy consumption on tropical urban heat island intensity: a review. Sustainable cities and society, 40, 677-687. doi: https://doi.org/10.1016/j.scs.2018.01.024

Hang, L., \& Tu, M. (2007). The impacts of energy prices on energy intensity: evidence from China. Energy Policy, 35(5), 2978-2988. doi: https://doi.org/10.1016/j.enpol.2006.10.022

Hartono, D., \& Resosudarmo, B. P. (2008). The economy-wide impact of controlling energy consumption in Pakistan: An analysis using a Social Accounting Matrix framework. Energy Policy, 36(4), 1404-1419. doi: https://doi.org/10.1016/j.enpol.2007.12.011

Howarth, R. B., Schipper, L., Duerr, P. A., \& Strøm, S. (1991). Manufacturing energy use in eight OECD countries: decomposing the impacts of changes in output, industry structure and energy intensity. Energy Economics, 13(2), 135-142. doi: https://doi.org/10.1016/0140-9883(91)90046-3

Hussain, M. S., Mosa, M. M., \& Omran, A. (2017). The Mediating Impact of Profitability on Capital Requirement and Risk Taking by Pakistani Banks. Journal of Academic Research in Economics, 9(3), 433-443.

Hussain, M. S., Ramzan, M., Ghauri, M. S. K., Akhtar, W., Naeem, W., \& Ahmad, K. (2012). Challenges and failure of Implementation of Basel Accord II and reasons to adopt Basel III both in Islamic and Conventional Banks. International Journal of Business and Social Research (IJBSR), 2(4).

Lecourt, M., Sigoillot, J.-C., \& Petit-Conil, M. (2010). Cellulase-assisted refining of chemical pulps: Impact of enzymatic charge and refining intensity on energy consumption and pulp quality. Process biochemistry, 45(8), 1274-1278. doi: https://doi.org/10.1016/j.procbio.2010.04.019

Lee, M., Keller, A. A., Chiang, P.-C., Den, W., Wang, H., Hou, C.-H., . . . Yan, J. (2017). Water-energy nexus for urban water systems: A comparative review on energy intensity and environmental impacts in relation to global water risks. Applied energy, 205, 589-601. doi: https://doi.org/10.1016/j.apenergy.2017.08.002

Mamić Sačer, I., \& Oluić, A. (2013). Information technology and accounting information systems' quality in Croatian middle and large companies. Journal of information and organizational sciences, 37(2), 117-126. doi: http://orcid.org/0000-0001-9125-8637

Nawaz, M. A., Afzal, N., \& Shehzadi, K. (2013). Problems of formally employed women: A case study of Bahawalnagar, Pakistan. Asian Journal of Empirical Research, 3(10), 12911299.

Nawaz, M. A., Azam, M. A., \& Bhatti, M. A. (2019). Are Natural Resources, Mineral and Energy Depletions Damaging Economic Growth? Evidence from ASEAN Countries. Pakistan Journal of Economic Studies, 2(2), 15-28.

Nicolaou, A. I. (2000). A contingency model of perceived effectiveness in accounting information systems: Organizational coordination and control effects. International Journal of Accounting Information Systems, 1(2), 91-105.

Recalde, M., \& Ramos-Martin, J. (2012). Going beyond energy intensity to understand the energy metabolism of nations: The case of Argentina. Energy, 37(1), 122-132. doi: https://doi.org/10.1016/j.energy.2011.07.011

Reddy, B. S., \& Ray, B. K. (2010). Decomposition of energy consumption and energy intensity in Indian manufacturing industries. Energy for Sustainable Development, 14(1), 35-47. doi: https://doi.org/10.1016/j.esd.2009.12.001 
Sadorsky, P. (2010). The impact of financial development on energy consumption in emerging economies. Energy Policy, 38(5), 2528-2535. doi: https://doi.org/10.1016/j.enpol.2009.12.048

Sajjad Hussain, M., Muhaizam Bin Musa, M., \& Omran, A. (2018). The Impact of Private Ownership Structure on Risk Taking by Pakistani Banks: An Empirical Study. Pakistan Journal of Humanities and Social Sciences, 6(3), 325-337.

Shen, B., Ding, X., Chen, L., \& Chan, H. L. (2017). Low carbon supply chain with energy consumption constraints: Case studies from China's textile industry and simple analytical model. Supply Chain Management: An International Journal. doi: https://doi.org/10.1108/SCM-05-2015-0197

Somavat, P., Jadhav, S., \& Namboodiri, V. (2010). Accounting for the energy consumption of personal computing including portable devices. Paper presented at the Proceedings of the 1st International Conference on Energy-Efficient Computing and Networking.

Vanek, F., \& Sun, Y. (2008). Transportation versus perishability in life cycle energy consumption: A case study of the temperature-controlled food product supply chain. Transportation research part D: Transport and environment, 13(6), 383-391. doi: https://doi.org/10.1016/j.trd.2008.07.001

Velasco, E., \& Roth, M. (2010). Cities as net sources of CO2: Review of atmospheric CO2 exchange in urban environments measured by eddy covariance technique. Geography Compass, 4(9), 1238-1259.

Xu, F., Xiang, N., Nijkamp, P., \& Higano, Y. (2013). Dynamic simulation of china's carbon intensity and energy intensity evaluation focusing on industry and energy structure adjustments by 2020. Environmental Engineering \& Management Journal (EEMJ), 12(10).

Yuan, J.-H., Kang, J.-G., Zhao, C.-H., \& Hu, Z.-G. (2008). Energy consumption and economic growth: evidence from China at both aggregated and disaggregated levels. Energy Economics, 30(6), 3077-3094. doi: https://doi.org/10.1016/j.eneco.2008.03.007

Zhao, H., Guo, S., \& Zhao, H. (2018). Impacts of GDP, Fossil Fuel Energy Consumption, Energy Consumption Intensity, and Economic Structure on SO2 Emissions: A MultiVariate Panel Data Model Analysis on Selected Chinese Provinces. Sustainability, 10(3), 657. doi: https://doi.org/10.3390/su10030657 